\title{
O CORPO FEMININO DESCOBERTO; ANÁLISE DA SEREIA DE TAKEUCHI KEISHÛ NO CONTEXTO EDITORIAL DA ERA MEIJI
}

Yoko Fujino

RESUMO: Numa sociedade que se pretendia tornar moderna, industrializada, enfim civilizada, como o Japão do final do século XIX, tudo que lembrava o aspecto animalesco do humano se mostrava impróprio. Extraindo da vida cotidiana os símbolos da organicidade como as excreções e as secreções, o Japão obteve sucesso em tornar a sua sociedade asséptica. Aqui, mostraremos a contribuição da imprensa no processo de regulamentação da visualidade do corpo.

RÉSUMÉ: Dans une societé que voulait se tourner moderne, industrializée, civilizée, comme le Japon du fin du siècle XIX, tout que souvenait l'aspect animalesque de l'humain était inádequat. En arrachant les signes d'organicité comme les excrétions et les sécrétions de la vie cotidienne, le Japon a obtenu succès en tornant sa societé asseptique. Ici, nous indiquons comment la presse a contribué dans le procès de la regulamentation de la visualitè du corps.

PALAVRAS-CHAVE: corpo, estrutura social, modernização, mulher, sexualidade.

KEYWORDS: corps, structure sociale, modernization, femme, sexualitè.

\section{O Corpo $\mathrm{Nu}$}

Neste artigo faremos um breve estudo do tratamento dado ao corpo feminino pela mídia japonesa feminina do início do século XX. Destacamos três casos encontrados na revista Jogakusekai, uma revista voltada para mulheres jovens solteiras. Nota-se que estes são os únicos casos por nós encontrados nos primeiros três anos da referida 
revista; dentre os títulos de revistas para mulheres jovens solteiras por nós pesquisados, são os primeiros casos de nu feminino, mesmo que parcial.

Desde a implantação da imprensa ilustrada moderna, em 1874', com o lançamento do jornal ilustrado Nichi Nichi Shinbun Onishiki, a figura feminina vem sendo objeto do olhar na sociedade japonesa. Ochiai Yoshiiku e Taiso Yoshitoshi, os primeiros ilustradores da imprensa da era Meiji, descendem da escola de ukiyo-e Utagawa Kuniyoshi, e a forma como eles representam a figura humana deixa clara a sua origem.

Pela pesquisa que realizamos nos arquivos de periódicos japoneses, a mais antiga revista para jovens mulheres que contém ilustrações é a revista Jogakusekai. Quando ela foi lançada, em 1901, o time de ilustradores foi formado por Mizuno Toshikata, discípulo de Taiso Yoshitoshi, e seus alunos, como Kaburagi Kiyokata, Ikeda Terukata, Mizuno (Ichikawa) Hidekata e Ikeda (Sakakibara) Shôen. Fizeram ainda parte da equipe de ilustradores Kajita Hanko, Takeuchi Keishû e Nakayama Kodô. A representação das figuras humanas naturalmente seguiu o estilo que cada escola desenvolvia fora das revistas.

As revistas femininas eram instrumento da modernização da sociedade japonesa. $\mathrm{Na}$ economia agrícola que predominava até então, a estrutura familiar, apesar de patriarcal, ainda estava fortemente ligada à figura da mulher, e a sua participação nos meios de produção era grande. A industrialização confinou a mulher à esfera familiar, desvinculando-a dos meios de produção. As revistas femininas indicavam o papel da mulher nesta nova sociedade.

Nota-se que as mulheres da classe baixa não deixam de participar do processo de produção. A mulher confinada é a mulher da classe média urbana que nasce com a modernização. A mulher que não trabalha é um símbolo de status ao homem, pois isto significa que o seu salário é suficiente para sustentar a família. Desvinculada do processo de produção, a mulher se torna consumidora de bens. Saber escolher o que e como consumir se torna o papel da mulher na família, e as revistas davam orientações neste sentido.

\section{O Imagiário ${ }^{2}$ do Corpo Feminino}

Para a nossa análise, escolhemos a revista Jogakusekai por ser a mais antiga revista voltada para o público feminino jovem, com ilustrações, por nós encontrada. As revistas para jovens mulheres que surgiram a seguir, como Shôjokai, da mesma editora Hakubunkan, Shôjo, da Joshibundansha, Shôjo da Jiji Shinpôsha e Shôjokai, da

1. Segundo Takahashi Katsuhiko, o primeiro jornal diário japonês foi Tokyo Nichi Nichi Shinbum, hoje Tokyo Mainichi Shinbum, lançado em fevereiro do ano 5 do Meiji (1872). O primeiro jornal ilustrado, ainda segundo o mesmo autor, foi o Tokyo Nichi Nichi Shinbum Ônishiki, lançado em julho de 1874. (Takahashi Katsuhiko, Shinbum nishiki-e no sekai, pp. 21-22).

2. Usamos aqui a expressão imagiário como conjunto de imagens que adquirem significação num dado contexto. Numa aula em 1996, o Prof. Dr. Antônio Luiz Cagnin sugeriu o uso desta expressão na ausência de tradução para a expressão inglesa imagery. 
Kinkô-dô Shoseki, seguiram o esquema editorial da revista Jogakusekai, e muitos de seus ilustradores surgiram nas páginas desta revista lançada em 1901.

A revista Jogakusekai foi lançada em 1901 com o intuito de auxiliar a formação das jovens mulheres numa época em que poucas tinham acesso às escolas médias. As páginas da revista seguiam a política do ryôsai-kenbo (boa esposa, mãe sábia), mostrando modelos de comportamento considerados exemplares.

O corpo descoberto aparece nestas revistas então apenas em contextos justificáveis como a amamentação - ou em planos distanciados do universo das leitoras. Assim, muitas figuras nuas são figuras notadamente ocidentais ou mitológicas. O primeiro registro de corpo feminino descoberto que encontramos na revista Jogakusekai é a figura de Maria e Jesus, na página 110 do oํ 11, ano 2. Este número foi um número especial dedicado à maternidade, e as páginas são ilustradas com a figura de Maria com o filho, em diferentes situações.

A ilustração em questão, de autoria desconhecida, mostra a Madona que amamenta o menino Jesus. O menino está em seu colo, com o rosto virado para o leitor. Maria olha para o filho, que está em seus braços, nus. A mão esquerda do menino segura o seio da mãe, que está à mostra. A imagem não mostra o momento da amamentação em si, mas o ato simbólico da amamentação, representado pelo seio descoberto.

No número 14 do mesmo ano, o corpo da revista é ilustrado com uma série de imagens sobre atendimento médico. $\mathrm{O}$ seu autor é provavelmente Yamamura Kôka, pois elas são assinadas com o hiragana "ya" e Kôka era o único artista desta fase cujo nome começava com "ya" Nas imagens, são mostrados médicos e enfermeiras em trajes ocidentais, diagnosticando e operando pacientes do sexo feminino. A inserção destas imagens provavelmente tem o intuito de mostrar como é feito o atendimento na medicina ocidental, que ainda era pouco difundida. A página 37 mostra um quadro com um médico com as mãos sobre o diafragma da paciente, com o peito descoberto, assistido por uma enfermeira.

No caso desta ilustração, o corpo da mulher não é mostrado de forma simbólica; tanto o seu corpo como os outros atores (a enfermeira e o médico) compõem uma cena demonstrativa da nova maneira de atendimento médico que se queria difundir. A imagem tem objetivo de quebrar provável resistência das mulheres em expor o seu corpo a um estranho.

A terceira aparição do nu feminino na revista Jogakusekai se dá no no 9 do ano 3. A imagem, provavelmente de autoria de Takeuchi Keishû, mostra uma mulher parcialmente coberta por plantas aquáticas. Mas a mulher não tem pernas, mas uma cauda de peixe. Ou seja, é uma sereia. Na mitologia japonesa existe o jugon, um ser meio humano, meio peixe, com aparência monstruosa. Mas a sereia que se vê na ilustração é o ser mitológico ocidental, apesar dos traços orientais.

Os três casos acima citados são os primeiros casos de imagem do nu feminino em revistas para jovens mulheres solteiras, segundo constatamos durante pesquisa de campo, realizada entre setembro de 1999 e fevereiro de 2000, nas bibliotecas do Congresso Japonês, Infantil de Osaka e Meiji Bunko da Universidade de Tóquio. Sendo estas imagens pioneiras da mídia impressa feminina jovem, podem ser entendidas como exemplos para os trabalhos que surgiram em seguida, nesta ou em outras editoras. 
Assim, podemos analisar a partir das três imagens, podemos analisar a condição do corpo feminino no final da era Meiji, sobretudo no que tange o discurso da sociedade patriarcal - representada pelas editoras - para as jovens mulheres. Observa-se que aspectos práticos ocidentais eram impostos com o intuito de alcançar uma sociedade/ economia moderna, enquanto alguns valores morais tradicionais eram mantidos e novas tradições eram incorporadas.

\section{A Condição do Corpo $\mathrm{Nu}$}

Até o final da era Meiji, o corpo nu ou parcialmente nu era facilmente encontrado no cotidiano das vilas e cidades: nas ruelas, mães amamentavam os filhos; as crianças corriam peladas; muitas atividades exigiam o corpo descoberto. Em gravuras e antigos registros fotográficos é possível observar trabalhadores e trabalhadoras nus ou quase nus, como pescadores, mergulhadores e carregadores. Para alguns tipos de trabalho, a roupa restringia o movimento do corpo; mas como resquício da civilidade era comum uso de símbolos "cobrindo" a nudez, como é o caso dos pescadores que amarravam um laço de palha na ponta do pênis (Ueno, 1998, p. 38).

Algumas trabalhadoras, como as ama, mergulhadoras que colhiam pérolas e moluscos, também trabalhavam nuas. Numa época em que não haviam tecidos sintéticos nem roupas de mergulho, a vestimenta impedia o movimento do corpo quando em contato com a água. Outras trabalhadoras, mesmo não estando em contato com a água, despiam-se da cintura para cima para ter maior liberdade de movimento dos braços.

Deste modo, o corpo nu, feminino ou masculino, não tinha conotação erótica. Ao contrário, o erotismo na cultura japonesa está mais relacionado ao corpo parcialmente coberto do que ao corpo totalmente descoberto. O erotismo nasce no desvelar, em pequenos detalhes que se expõe. A relação corpo nu-erotismo surge com a ocidentalização do Japão, quando corpos expostos tornaram-se interditos.

A interdição e a erotização do corpo nu não foi um ato espontâneo da sociedade japonesa. Um dos casos mais conhecidos de interdição do corpo aconteceu no ano 28 da era Meiji (1895), quando a obra Chôshô, de Kuroda Seiki, escandalizou setores da sociedade japonesa. Kuroda, recém retornado da Europa, pintou uma mulher nua de costas, que se vê no espelho. Esta obra se perdeu durante a Segunda Guerra Mundial. Diz-se que quando o imperador Meiji visitou a exposição os organizadores tiveram o cuidado de envolver a pintura com um tecido, para esconder a metade inferior da figura nua (Ishiko, 1988, pp. 48-49). Este acontecimento serviu de tema para o cartunista francês Georges Bigot, que ironizou a contradição da sociedade japonesa que tolerava o nu na vida cotidiana mas o repelia quando era registrado em obras de arte (ibidem).

Um outro caso de interdição pública foi a proibição e apreensão da revista de literatura e artes Myôjô de novembro de 1900, por causa de uma figura feminina nua (Shimada, 1999, p. 42). O artigo de Shimada não cita qual imagem havia sido censurada, mas procurando nos nossos arquivos encontramos a imagem de uma mulher nua, reclinada no divã. É a reprodução de uma pintura de Herzoy Karl August Von Weimar, intitulada Marmorschön, doch marrnarkalt. Esta imagem ilustra o diálogo de Yosano 
Tekkan e Ueda Toshi, no qual artistas plásticos do Hakuba-kai ${ }^{3}$ são avaliados. Na página em que aparece a figura em questão Tekkan e Ueda avaliam um nu de Fujishima Takeji, discutindo justamente se o nu deve ser considerado belo ou não (Myôjô, 8, pp. 6-7).

\section{A Significação do Corpo Feminino}

Os três casos de nudez feminina publicados na revista Jogakusekai, citados no início deste artigo, podem ser vistos como metáforas do tratamento dado ao corpo feminino na sociedade japonesa do século XX.

A imagem da Maria com o seio nu trata o corpo feminino pelo seu aspecto biológico-reprodutivo: a sua função é procriar e nutrir o filho. Tudo em seu corpo converge para a reprodução. O uso da figura de Maria parece indicar o ideal da sexualidade feminina. Jesus é filho de Deus, e não de um homem; ou seja, foi gerado de uma relação assexuada, asséptica.

Lembramos que no Japão pré-moderno as relações entre homens e mulheres eram bastantes livres nos campos e nas camadas mais baixas da população. Muitos casamentos eram assumidos só após o nascimento do primeiro filho. Em algumas regiões, os jovens tinham a sua iniciação sexual através de mulheres casadas. $\mathrm{O}$ concubinato também era comum nas cidades.

O governo Meiji, com o objetivo de adequar a sociedade japonesa aos princípios ocidentais modernos, cria normas como a proibição do concubinato e a instituição do sistema de registro de famílias. A obrigatoriedade do registro de matrimônios e nascimentos desestimulou as relações pré-maritais, numa época em que métodos contraceptivos e abortivos eram precários.

Para evitar a gravidez pré-matrimonial, e mais ainda, para que o casamento se tornasse instrumento de ascensão social, manutenção do status ou de aliança entre as famílias, criaram-se obstáculos para dificultar o contato entre jovens de sexo oposto e evitar que a escolha do parceiro fosse feita pelos próprios envolvidos. Enquanto a união era resultado de convivência dos envolvidos, o relacionamento entre homens e mulheres era baseado nas afinidades; mas a partir do momento em que a escolha é feita pela família, o relacionamento acaba se tornando instrumento para continuidade do clã, e a maternidade passa a ser o objetivo da união.

A imagem da Maria com o seio nu parece indicar esta nova diretriz: o seio, muitas vezes utilizado como símbolo da sexualidade feminina, só se torna digno de nota quando em função do filho. $\mathrm{O}$ corpo não pertence à mulher: ela é o meio onde se concretiza a continuidade da espécie.

3. Grupo de estudos de pintura em técnica ocidental, fundado por Kuroda Seiki, Fujishima Takeji e Okada Saburôsuke. Freqüentaram este grupo jovens talentos do final da era Meiji, como Hashimoto Kunisuke, Ichijô Narumi e Takehisa Yumeji. Destaca-se a importância deste grupo na evolução das artes gráficas japonesas, pela participação de seus membros no mercado editorial japonês da primeira metade do século XX, e no estabelecimento da pintura ocidental no Japão, uma vez que seus fundadores foram responsáveis pela sua introdução do curso de pintura ocidental na Faculdade de Belas Artes de Tóquio. 
A segunda imagem, que mostra o médico diagnosticando a doença no corpo da mulher, aparentemente está ligada ao aspecto biológico do corpo. A cena mostra o médico, em trajes ocidentais, que faz o diagnóstico tocando no corpo de uma mulher, que jaz sobre uma maca. Ela veste trajes orientais, mas está despida da cintura para cima. A cena é observada por uma enfermeira, também em trajes ocidentais.

Já afirmamos no início do artigo que esta imagem foi provavelmente inserida para mostrar às leitoras como seria o atendimento na medicina alopática ocidental, como parte do esforço em difundi-lo. Mas a cena não se restringe à prática médica: ela pode condensar em si a introdução dos hábitos ocidentais nas famílias japonesas.

$\mathrm{Na}$ tese Identidade e alteridade; a figura feminina nas revistas ilustradas japonesas nas eras Meiji, Taisho e Shôwa ${ }^{4}$ demonstramos que a mulher teve importante papel na modernização da sociedade e da economia japonesas, ao se tornar responsável pelo bem-estar da família e pela boa aplicação do salário pelo trabalho do homem. Ainda que o papel de chefe da família tenha sido oficialmente do homem, ela se tornou o eixo da família, cuidando da saúde, alimentação, vestuário, educação dos filhos. Muitas destas atribuições eram tradicionalmente do homem, mas a industrialização exigiu dele maior tempo e dedicação, o que acabou por concentrar a maioria das atividades do lar às mãos das mulheres.

Aliás, o próprio lar é um conceito novo para os japoneses da era Meiji. Antes da restauração Meiji, a união em torno das famílias era muito estreita. A família compreendia o casal chefe da família, seus filhos, netos e agregados, como os irmãos mais jovens, empregados etc. Esta organização familiar era voltada à economia agrícola, uma vez que a união em torno de um único chefe resultava na concentração de terras, e a família numerosa representava abundância de mão de obra. Mas a mudança da economia da agrária para a industrial e a restauração do sistema de governo em torno de um Imperador demandava mudanças na estrutura familiar. $\mathrm{O}$ sistema de registros passou a considerar família a unidade composta pelo casal e seus filhos, restringindoa a apenas duas gerações.

Excluindo os velhos da família, abre-se perspectiva para a aquisição de novos hábitos. As revistas femininas foram usadas como um instrumento para a inserção de alguns costumes ocidentais que o governo japonês desejava incluir no novo modelo de família japonesa. A maioria destes costumes relaciona-se à saúde e à alimentação que de algum modo estão interligados. Introduziram-se hábitos como a ingestão da carne e do leite, com a publicação de receitas; o exame pré-natal, através de depoimentos de parteiras; e a poupança, com conselhos sobre a economia do lar.

A segunda imagem então pode ser entendida como a lembrança do fato da mulher ser a engrenagem da nova família japonesa, da qual dependia o bom funcionamento da nova estrutura social e econômica.

Podemos observar a mistura dos mitos japoneses e ocidentais na terceira figura. Nela se vê um ser meio humano, meio peixe, com o corpo parcialmente encoberto pela vegetação marinha. Para nós, hoje, parece ser uma sereia; mas como este ser teria sido

4. Yoko Fujino, Identidade e Alteridade, passim. 
visto no Japão de 1903? Mesmo que a identificasse como sereia, seria ela sereia dos contos de Andersen ou da Odisséia?

A imagem, do tipo koma-e, está inserida numa página cujo texto verbal não tem relação com a imagem. Na revista Jogakusekai o koma-e costuma seguir a linha editorial, ou seja, as imagens dispostas em páginas distintas são seriadas, tendo um tema em comum. Noutros casos os koma-e aparentemente não seguem o editorial, mas podem ter um tema em comum como a estação do ano. Neste caso, pode-se afirmar que a série de koma-e tem um discurso distinto do editorial. Mas em ambos os casos é possível afirmar que o discurso do koma-e é distinto do discurso do artigo que ocupa a mesma página. Quando a imagem e o texto verbal seguem o mesmo discurso, a imagem não é koma-e, e sim sashi-e. Assim, é impossível buscar no verbal subsídios para entendimento desta imagem.

$\mathrm{Na}$ fauna do imaginário japonês existe um ser chamado jugon, na verdade um mamífero marinho. Mas no imaginário popular, jugon é um monstro marinho. Lafcadio Hearn, em Kwaidan, narra a história de um ser marinho que, salvo por um homem, retribui-lhe chorando lágrimas de rubi. Nas narrativas de Hearn há um número expressivo de seres da água; e observa-se que a maioria delas está ligada à morte. São seres sob forma de jovens e belas mulheres que seduzem os homens e os puxam para a água, tirando-lhes a vida.

Quanto à sereia da cultura ocidental, não sabemos quando os japoneses tiveram contato com ela; mas a aparência física da sereia da ilustração de Jogakusekai é baseada na imagem ocidental da sereia dos contos de Andersen ${ }^{5}$ : mulher da cintura para cima e peixe da cintura para baixo. Qualquer que seja a sereia em que o autor tenha se baseado, ela não é humana.

E é justamente nesta condição não-humana que este ser apresenta-se nu. A arte européia também mostrou o nu através das mitologias por longo tempo, e Olympia e Le déjeuner sur l'erbe escandalizaram por mostrar a figura feminina nua como figura humana, e não sob forma de deusa ou de outro ser mitológico. Apesar de parcialmente coberta, a nudez da sereia de Keishû é aceita por ser uma exceção: não sendo humana, está excluída da regra dos humanos.

Este consentimento também pode ser visto em outros nus: a publicidade do cosmético Crème Lait, publicadas nas revistas femininas do final da era Meiji, mostra uma mulher de traços ocidentais nua da cintura para cima, com um laço cobrindo os seus seios. A publicidade supostamente não ofenderia nem desonraria as mulheres japonesas porque a figura mostrada tem os traços ocidentais: ela pertence a um mundo à parte, onde as regras sociais japonesas não valem.

\section{As Diversas Mulheres}

O uso do corpo feminino como signo erótico é diferente no Japão e na cultura ocidental. Mas no Japão da virada do século XIX para XX o corpo feminino aparece

5. Lembramos que em diversas mitologias e narrativas antigas as sereias assumem formas humanas da cintura ou do pescoço para cima, sendo o restante do corpo ave ou peixe. Quanto à Odisséia, Homero não faz referência ao aspecto físico das sereias que seduzem marujos com seu canto. 
como signo da sexualidade em obras de poetas do sexo feminino como Yosano (Hou) Akiko. Em Onna uta no hyakunen (100 anos de poesia feminina) Michiura Motoko analisa o uso do seio como expressão da feminilidade e sexualidade nos onna uta (poesia feminina). Michiura indica que em Midaregami, de Yosano (Hou) Akiko, aparecem três poemas em que a expressão chibusa (seio) é usada como signo da sexualidade feminina.

Um dos poemas diz:

\section{Chibusa osae shimpi no tobari sotokerinu kokonaru hana no kurenai zo koki}

Michiura interpreta-o da seguinte forma:

Ao te amar, sinto que todos os sentimentos inexprimíveis que comprimiam o meu seio (eu como um todo), tudo aquilo que parecia misterioso e enigmático, se dissiparam. E assim como a beleza de uma flor vermelha se sobressai após dissipar a neblina, tenho a sensação de manifestar aqui a minha existência (Michiura, 200, p. 7).

Para uma parcela da população feminina que tinha o hábito de ler revistas literárias o seio já aparecia como signo da sexualidade feminina. Devido à repercussão da coletânea de poemas de Yosano Akiko na época, é provável que leitoras da revista Jogakusekai fossem também leitoras dos poemas de Yosano Akiko. Ademais, Sasaki Nobutsuna, colaborador de Jogakusekai que avaliava os poemas enviados por leitoras à revista, era crítico feroz da obra da poetiza.

Assim, é possível observar os três nus que aparecem em Jogakusekai como tentativa de modalização do olhar das leitoras para o corpo feminino. Nos dois primeiros exemplos, em que o nu feminino aparece como signo da maternidade e como meio de modernização da estrutura social, o corpo feminino é consentido e até prescrito. Mas no terceiro caso, o da sereia, o corpo feminino é interdito, ora pela vegetação que a cobre ora pela sua marginalização.

Independente da sereia a que o desenho de Keishû se refere, a nudez feminina aqui é signo da sexualidade feminina: seja pela paixão que a sereia de Andersen nutre, seja pela sedução da sereia da Odisséia ou dos seres da água de Lafcadio Hearn, ela incorpora o desejo feminino. Elas enfrentam, diretamente ou indiretamente, as interdições impostas pela sociedade humana patriarcal, em que o racional prevalece sobre o passional. Assim, elas representam o embate da paixão contra a razão.

A sanção a elas dada não apenas é a morte, mas a sua total eliminação ou a negação de seu fim como ser vivo: a figura de Andersen torna-se espuma, desaparecendo entre as ondas do mar; em Odisséia as figuras femininas têm as suas características como seres vivos (mesmo que não humanos) negados ao serem transformadas em pedra. Nos casos dos seres da água de Hearn, descobre-se que a figura feminina que encanta o personagem é na verdade um grotesco sapo: ela não só é descoberta na sua forma não humana, como também no valor agregado à feminilidade, a beleza. Como pena máxima, ela é morta quando se encontra na forma de um grotesco sapo. Não é a nudez propriamente dita que incomoda o status quo da sociedade patriarcal, mas é o significado que ela adquire. 
A consciência do desejo torna-se empecilho para o casamento arranjado e para a construção da estrutura social adequada à industrialização baseada na divisão de tarefas no ambiente familiar. A "modernização" acabou separando as mulheres em dois grupos: as mulheres designadas à família (reprodução e manutenção do lar) e as mulheres designadas às paixões (sexo sem fins reprodutivos). A ilustração de Keishû mostra a figura feminina que se deixa dominar pela paixão, tornando-se marginal na sociedade patriarcal.

Em Andersen, a sereia não obtém o amor do príncipe e se atira ao mar. Na mitologia grega, as sereias, quando não conseguem seduzir, se atiram ao mar e se transformam em rochas. Que fim teria levado a sereia de Keishû?

\section{Bibliografia}

ARdEnNE, Paul. L'image corps; figures de l'humain das l'art du XXe siécle. Paris, Éditions du Regard, 2001.

FujINO, Yoko. Identidade e Alteridade; a Figura Feminina nas Revistas Ilustradas Japonesas nas Eras Meiji, Taisho e Shôwa. Tese de doutorado. Escola de Comunicações e Artes, Universidade de São Paulo, 2002. Material não publicado.

ISHIKO, Jun. Nihon manga-shi (História das HQs no Japão). Tokyo, Shakaishisô-sha, 1988.

MichIURA, Motoko. "Onna uta no hyakunen" ("Cem Anos de Poesia Feminina"). In AOKI, Tamotsu et alii. Onna no bunka (A Cultura das Mulheres). Tokyo, Iwanami, 2000.

MOROHASHI, Taiki. Zasshi bunka no naka no joseigaku (The culture of women's magazines: a study of gender image). Tokyo, Akashi Shoten, 1996.

SHIMADA, Norio. Alphonse Mücha. Tokyo, Rikuyôsha, 1999.

UENO, Chizuko. Hatsujô sôchi; erosu no sinario (The erotic apparatus). Tokyo, Chikuma Shobô, 1998. YAMATANE, Bijutsukan. Bijin-ga no tanjô (The birth of bijin-ga). Tokyo, Yamatane Art Museum, 1997.

\section{Notas}

Takeuchi Keishû (1861-1943)

Foi discípulo e filho adotivo de um dos ramos da escola Kanô, mas estudou também com Tsukioka Yoshitoshi. Fez ilustrações para o Chûou Shinbum em estilo ukiyo-e. Foi editor de arte das revistas Taiyô, Bungei Kurabu e Shônen Sekai, todas publicadas pela editora Hakubunkan. Participou da revista Jogakusekai desde o seu primeiro ano, desenhando mulheres no estilo nihon-ga. Fez também suas capas, como nos números 1,8 e 10 do ano 3. Depois do ano 4 não há referências a este artista nos índices da revista.

Yamamura Kôka (1885-1942)

Foi aluno de Ogata Gekkô e se formou em nihon-ga pela Faculdade de Belas Artes de Tóquio. Fez ilustrações para as revistas Jogakusekai e Shôjosekai, fazendo também as capas deste último, por volta de 1911. Fez também ilustrações para a revista Chûgaku Sekai. O texto do catálogo Bijin-ga no tanjô destaca o fato do artista ter sido premiado em diversos salões de artes do nihon-ga, tendo ao mesmo tempo demonstrado interesse nos artistas europeus como Matisse, Corot, Millet e Rousseau. 